\title{
Commentary: Preliminary Evidence for Training-Induced Changes of Morphology and Phantom Limb Pain
}

\author{
Jaskaran Chagger ${ }^{1}$, Krishihan Sivapragasam ${ }^{1}$ and Michael Wong ${ }^{2 *}$ \\ ${ }^{1}$ Bachelor of Health Sciences Program, McMaster University, Hamilton, ON, Canada, ${ }^{2}$ Psychology Department, University of \\ Wisconsin - La Crosse, La Crosse, WI, United States
}

Keywords: phantom limb pain (PLP), vision, passive stimulation, virtual reality (VR), tactile feedback, active training

\section{A Commentary on}

Preliminary Evidence for Training-Induced Changes of Morphology and Phantom Limb Pain by Preißler, S., Thielemann, D., Dietrich, C., Hofmann, G. O., Miltner, W. H. R., and Weiss, T. (2017). Frontiers in Human Neuroscience 11:319. doi: 10.3389/fnhum.2017.00319

\section{INTRODUCTION: PHANTOM LIMB PAIN}

\section{OPEN ACCESS}

Edited by:

Filippo Brighina,

University of Palermo, Italy

Reviewed by:

Giovanni Pellegrino,

Montreal Neurological Institute and Hospital, McGill University, Canada

Elisabetta Ambron,

Scuola Internazionale Superiore di

Studi Avanzati (SISSA), Italy

Mariella Pazzaglia,

Sapienza University of Rome, Italy

${ }^{*}$ Correspondence:

Michael Wong

mwong@uwlax.edu

Received: 24 February 2019 Accepted: 04 June 2019

Published: 19 June 2019

Citation:

Chagger J, Sivapragasam K and Wong M (2019) Commentary:

Preliminary Evidence for

Training-Induced Changes of Morphology and Phantom Limb Pain.

Front. Hum. Neurosci. 13:211. doi: 10.3389/fnhum.2019.00211
Phantom limb pain (PLP) is a chronic pain disorder characterized by painful sensations that are perceived to arise from the missing limb, presumably due to structural and functional alterations in several regions of the brain (i.e., anterior midcingulate cortex, aMCC; Preißler et al., 2017). In Preißler et al. (2017), upper-limb amputees were trained to use a myoelectric prosthetic arm (equipped with somatosensory feedback and a grip sensor) in an attempt to reduce PLP. After a 2-week training period, a reduction in PLP and an improvement in prosthetic performance was found in amputees (Preißler et al., 2017). Additionally, reduction in PLP was correlated with cortical thickness changes in the visual streams and pain processing centers ipsilateral to the amputation (Preißler et al., 2017). In this commentary, we will comment on the effectiveness of tactile stimulation, attention, and visual reliance in PLP reduction. We propose further that a combination of all these elements may be most beneficial in the treatment of PLP.

\section{ACTIVE vs. PASSIVE STIMULATION}

In Preißler et al. (2017), participants' PLP reduced after being trained to actively use a prosthetic arm to perform manual dexterity tasks (e.g., Tower of Hanoi). Because participants were required to actively attend to the stimuli in Preißler et al. (2017), it is difficult to decouple the effects of attention and tactile stimulation in PLP reduction. Several studies have reported that transcutaneous electrical nerve stimulation (TENS), a device that electrically stimulates the skin, is effective in reducing PLP in the absence of active participation (Finsen et al., 1988; Katz and Melzack, 1991; Johnson, 2014; Tilak et al., 2016). This suggests that tactile stimulation alone may be sufficient in alleviating the pain associated with the missing limb. Interestingly, however, a study conducted by Moseley et al. (2008) found that stimulation coupled with active participation (i.e., discriminating tactile stimuli) induced greater pain reduction among individuals who suffer from chronic pain than tactile stimulation alone. Although chronic pain may differ from PLP in its mechanism, this finding nevertheless suggests the effectiveness of Preißler et al. (2017) myoelectric prosthetic arm may be a result of the active training period, which required participants to perform manual dexterity tasks. 


\section{VISUAL RELIANCE}

In addition to reporting a decrease in PLP among the participants after the training period, Preißler et al. (2017) also reported a reduction in the cortical thickness of the occipital cortex. The authors suggest this reduction might reflect reduced visual usage as the participants became reliant on the somatosensory feedback provided by the prosthetic arm (Preißler et al., 2017). Interestingly, several studies have proposed that visual engagement alone is capable of reducing PLP. Ramachandran and Altschuler (2009), for example, found that mirror box therapy-a technique that creates a visual illusion of the amputated limb-was effective in reducing PLP (Finn et al., 2017). Other studies have similarly found the importance vision plays in PLP reduction. For example, both participants in Tung et al. (2014) - who visually observed another's limbs-and Ambron et al. (2018) - whose vision was engaged with virtual reality (VR)-experienced reductions in PLP.

\section{COMBINED EFFECTS OF TOUCH, ATTENTION, AND VISION}

Recent advances in VR technology provide a promising avenue for the future of PLP treatment. Similar to the myoelectric prosthetic arm protocol utilized by Preißler et al. (2017), immersive VR technology can combine tactile feedback, active participation, and visual reliance, elements discussed above that have the potential to reduce PLP. Ichinose et al. (2017), for example, required participants to perform an active VR task that coupled visual stimuli (i.e., virtual objects) with tactile feedback. In this task, the participants' missing upper limb was projected in the VR environment as a mirror image of their intact upper limb. The authors found that when participants were trained to touch a virtual object with their missing limb (by moving their intact limb), they experienced greater reductions in PLP when their cheek was simultaneously touched (than when no tactile stimuli were presented; Ichinose et al., 2017). Thus, similar to myoelectric prosthetics, VR provides researchers and clinicians with an accessible (potentially cost-effective) approach to effectively reduce PLP.

\section{POSSIBLE MECHANISMS FOR PLP REDUCTION}

Although we discuss various beneficial approaches to reducing PLP, it is important to acknowledge that the benefits of the interventions discussed above vary among patients, with some patients who report no PLP reductions (see for example

\section{REFERENCES}

Ambron, E., Miller, A., Kuchenbecker, K. J., Buxbaum, L. J., and Coslett, H. B. (2018). Immersive low-cost virtual reality treatment for phantom limb pain: evidence from two cases. Front. Neurol. 9:67. doi: 10.3389/fneur.2018.00067
Ortiz-Catalan et al., 2014; Imaizumi et al., 2017). The studies discussed above nevertheless provide insight into the mechanisms explaining PLP reduction. Thus far, we have described studies where PLP is reduced in interventions that involve touch alone (e.g., TENS) and vision and attention (e.g., mirror box therapy). This suggests that PLP may involve an interplay of touch, attention, and vision. There is much evidence in the literature to suggest these interactions exist. For example, several studies have reported that the rubber hand illusion has the potential to reduce pain (e.g., Lenggenhager et al., 2013; Pazzaglia et al., 2016; Fang et al., 2019); and other studies have suggested vision may influence tactile perception (e.g., TaylorClarke et al., 2002; Harris et al., 2007). Additionally, reports of PLP reduction with mirror box therapy suggests vision and attention may play a crucial role, possibly by increasing one's sense of agency of the missing limb. Although further research is necessary to investigate this possibility, Imaizumi et al. (2017) reported that while mirror box therapy increased sense of agency, it did not lower reports of PLP.

\section{CONCLUSIONS AND FUTURE DIRECTIONS}

In conclusion, PLP therapy has been extensively explored in the literature. In Preißler et al. (2017), the authors follow a similar approach taken by Moseley et al. (2008), where somatosensory feedback is coupled with an active training component. Moseley et al. (2008) reported that coupling tactile stimulation with an active component is more effective in reducing PLP than passive approaches. However, passive stimulation is capable of reducing PLP as well (i.e., TENS; Finsen et al., 1988; Katz and Melzack, 1991; Johnson, 2014; Tilak et al., 2016). Furthermore, Preißler et al. (2017) suggest their participants were relying less on vision as they became familiar with the prosthetic arm; intriguingly, the literature suggests engaging the visual system is actually beneficial to PLP reduction (see for example Ramachandran and Altschuler, 2009; Finn et al., 2017; Ambron et al., 2018). Recently, studies using immersive VR technology have supported interventions that incorporate tactile feedback, attention, and vision (Ichinose et al., 2017). Furthermore, in future studies, it would be interesting to investigate the functional neural changes that may accompany increased usage of a myoelectric prosthetic arm.

\section{AUTHOR CONTRIBUTIONS}

All authors listed have made a substantial, direct and intellectual contribution to the work, and approved it for publication.

Fang, W., Zhang, R., Zhao, Y., Wang, L., and Zhou, Y.-D. (2019). Attenuation of pain perception induced by the rubber hand illusion. Front. Neurosci. 13:261. doi: $10.3389 /$ fnins.2019.00261

Finn, S. B., Perry, B. N., Clasing, J. E., Walters, L. S., Jarzombek, S. L., Curran, S., et al. (2017). A randomized, controlled trial of mirror therapy for 
upper extremity phantom limb pain in male amputees. Front. Neurol. 8:267. doi: 10.3389/fneur.2017.00267

Finsen, V., Persen, L., Lovlien, M., Veslegaard, E., Simensen, M., Gasvann, A., et al. (1988). Transcutaneous electrical nerve stimulation after major amputation. J. Bone Joint Surg. 70-B, 109-112. doi: 10.1302/0301-620X.70B1.3257494

Harris, J. A., Arabzadeh, E., Moore, C. A., and Clifford, C. W. G. (2007). Noninformative vision causes adaptive changes in tactile sensitivity. J. Neurosci. 27, 7136-7140. doi: 10.1523/JNEUROSCI.2102-07.2007

Ichinose, A., Sano, Y., Osumi, M., Sumitani, M., Kumagaya, S., and Kuniyoshi, Y. (2017). Somatosensory feedback to the cheek during virtual visual feedback therapy enhances pain alleviation for phantom arms. Neurorehabil. Neural Repair 31, 717-725. doi: 10.1177/1545968317718268

Imaizumi, S., Asai, T., and Koyama, S. (2017). Agency over phantom limb enhanced by short-term mirror therapy. Front. Hum. Neurosci. 11:183. doi: 10.3389/fnhum.2017.00483

Johnson, M. I. (2014). Transcutaneous Electrical Nerve Stimulation (TENS): Research to Support Clinical Practice. New York, NY: OUP Oxford.

Katz, J., and Melzack, R. (1991). Auricular transcutaneous electrical nerve stimulation (TENS) reduces phantom limb pain. J. Pain Symptom Manage. 6, 73-83. doi: 10.1016/0885-3924(91)90521-5

Lenggenhager, B., Scivoletto, G., Molinari, M., and Pazzaglia, M. (2013). Restoring tactile awareness through the rubber hand illusion in cervical spinal cord injury. Neurorehabil. Neural Repair 27, 704-708. doi: 10.1177/1545968313491009

Moseley, L. G., Zalucki, N. M., and Wiech, K. (2008). Tactile discrimination, but not tactile stimulation alone, reduces chronic limb pain. Pain 137, 600-608. doi: 10.1016/j.pain.2007.10.021

Ortiz-Catalan, M., Sander, N., Kristoffersen, M. B., Håkansson, B., and Brånemark, R. (2014). Treatment of phantom limb pain (PLP) based on augmented reality and gaming controlled by myoelectric pattern recognition: a case study of a chronic PLP patient. Front. Neurosci. 8:24. doi: 10.3389/fnins.2014. 00024

Pazzaglia, M., Haggard, P., Scivoletto, G., Molinari, M., and Lenggenhager, B. (2016). Pain and somatic sensation are transientlynormalized by illusory body ownership in a patient with spinal cord injury. Restor. Neurol. Neurosci. 34 603-613. doi: 10.3233/RNN-150611

Preißler, S., Thielemann, D., Dietrich, C., Hofmann, G. O., Miltner, W. H. R., and Weiss, T. (2017). Preliminary evidence for training-induced changes of morphology and phantom limb pain. Front. Hum. Neurosci. 11:319. doi: 10.3389/fnhum.2017.00319

Ramachandran, V. S., and Altschuler, E. L. (2009). The use of visual feedback, in particular mirror visual feedback, in restoring brain function. Brain 132, 1693-1710. doi: 10.1093/brain/awp135

Taylor-Clarke, M., Kennett, S., and Haggard, P. (2002). Vision modulates somatosensory cortical processing. Curr. Biol. 12, 233-236. doi: 10.1016/s0960-9822(01)00681-9

Tilak, M., Isaac, S. A., Fletcher, J., Vasanthan, L. T., Subbaiah, R. S., Babu, A., et al. (2016). Mirror therapy and transcutaneous electrical nerve stimulation for management of phantom limb pain in amputees - a single blinded randomized controlled trial: mirror therapy versus TENS for phantom limb pain. Physiother. Res. Int. 21, 109-115. doi: 10.1002/pri.1626

Tung, M. L., Murphy, I. C., Griffin, S. C., Alphonso, A. L., Hussey-Anderson, L., Hughes, K. E., et al. (2014). Observation of limb movements reduces phantom limb pain in bilateral amputees. Ann. Clin. Trans. Neurol. 1, 633-638. doi: $10.1002 / \operatorname{acn} 3.89$

Conflict of Interest Statement: The authors declare that the research was conducted in the absence of any commercial or financial relationships that could be construed as a potential conflict of interest.

Copyright (C) 2019 Chagger, Sivapragasam and Wong. This is an open-access article distributed under the terms of the Creative Commons Attribution License (CC BY). The use, distribution or reproduction in other forums is permitted, provided the original author(s) and the copyright owner(s) are credited and that the original publication in this journal is cited, in accordance with accepted academic practice. No use, distribution or reproduction is permitted which does not comply with these terms. 